International Journal of Medicine, $9(1)(2021) 58-59$
SPC
Website: $w w w . s c i e n c e p u b c o . c o m / i n d e x . p h p / I J M$
Research paper

\title{
Patient autonomy
}

\author{
Muneerah Albugami ${ }^{1}$ *, Usamah El Alem ${ }^{1}$ \\ ${ }^{1}$ Medicine Department, King Faisal Specialist Hospital and Research Centre, Riyadh, Saudi Arabia \\ *Corresponding author E-mail: drmb99@yahoo.com
}

\begin{abstract}
Patient autonomy is one of the most important ethical values in the health care practice. Patients' autonomy means the right of patients to make decisions about their medical care without their health care provider trying to influence the decision. Patients' autonomy allows health care providers to educate the patients but do not allow them to make the decision for the patients.
\end{abstract}

Keywords: Autonomy, Competent, Decision, Conflict, Challenge

\section{Introduction}

We present the case of a 70-year-old female who had hypertension, diabetes, dyslipidemia, dilated cardiomyopathy, her ejection fraction was $30 \%$ and she had normal coronary arteries. She had history of resection of sigmoid colon cancer in 2002 , followed by chemotherapy and she was on remission since 2007. She had osteoarthritis of both knee joints. She had persistent right hip pain, it was slightly improved with Tylenol (acetaminophen), it interfered with her daily activates and sleep. This pain was different from her usual knee osteoarthritis pain. No history of groin pain or trauma or fever or back pain or muscle weakness or abnormal peripheral sensation or sphincter disturbance. Her right hip examination showed no tenderness, the length of legs was equal, there was limited internal rotation and flexion (The movement of the joint was very painful), no muscle weakness, her pain sensation was intact, and no lumbosacral spine tenderness. Her general physical examination was unremarkable. Xray of the right hip showed osteoarthritic changes. A computerized tomography (CT) scan of hip showed a destructive osseous lesion with soft tissue component in the posterior column of the right acetabulum in keeping with bone metastasis. There was another well-defined lytic lesion with sclerotic margins noted in the right femoral head. Whole body bone scan showed right acetabulum and right femoral head increased uptake in addition to increased tracer uptake of the left humeral head in keeping with metastatic bone disease. The hip biopsy showed metastatic carcinoma consistence with thyroid origin. Fine needle aspiration of thyroid showed follicular thyroid carcinoma with bone metastasis. Patient refused surgery (total thyroidectomy). She had frequent meeting with internal medicine and surgical teams to explain to her the importance of the surgery in her medical management. According to the psychiatrist she was competent and capable to make her treatment decision. Her two sons were contacted and they agreed that their mother capable to make her decision.

What to do when a competent patient refuse treatment? It is a big challenge to accept that patient's choosing of no treatment with a high chance of suffering. Competent patients have the ability to make their own decisions, regardless of consequences. Physician must respect a competent patient's decision to refuse an investigation or treatment even if physicians think the patient's decision wrong. The physician should know the patients' autonomy which is the right of patients to make decisions about their medical care without their health care provider trying to influence the decision. Patients' autonomy allows for health care providers to educate the patients but do not allow them to make the decision for the patients [1]. Two conditions are essential for autonomy: liberty (independence for controlling influences) and agency (capacity for intentional action) [2], [3]. Sometimes what the professional believes is best for the patient is not what the patient wants to do. Conflict can arise around this concept when what the physician believes is in the best interest of the patient differs from what the patient wants. When a patient's decisions conflict with what medical teams believe is in the best interests of the patient, the physicians should respect and-patients' autonomy [4].

The relationship between the physician and the patient is based on trust and communication. Patients should have the information needed to understand the risks and benefits of a planned intervention. The patients should be given choices and allowed to make decisions. The physician needs to ensure the patient truly understands, taking the time when needed to counsel and listen to patients so that they can make informed decisions. They should know the consequences if they choose no intervention or no treatment. The physician must not put pressure on the patients to accept their advice.

Patients are facing not just the effects of the disease on their body, but also the disease will limit their life. The disease can affect a patient's autonomy by challenging life plans, changes in relationships and disrupting self-identities [5]. Disease can impair autonomy by restricting self-development skills and undermining self-evaluations [6]. Patients with full capacity have the right to transfer their autonomy to others: to a family member, friend, or to his/her physician. In cases of patients unable to decide for themselves and therefore with limited autonomy, surrogate decision-making is justified. 
Sometimes patients make their decision based on their religious beliefs and values. Patients may choose faith over medicine. Physicians must remain neutral regarding religion. Physicians need to learn to respect the decisions that patients make based on their religious believes and not become offended.

This case highlights the importance to respect and trust patients' autonomy. It is a professional medical ethics and it should be part of physician's professional duties.

\section{Declaration of patient consent}

The author certify that they have obtained all appropriate patient consent for publication in the Journal.

\section{Financial support and sponsorship}

Nil.

\section{Conflicts of interest}

There are no conflicts of interest.

\section{References}

[1] Beauchamp TL, Childress JF. Principles of biomedical ethics. 6. New York: Oxford University Press; 2009.

[2] Ion Arrieta Valero Autonomies in Interaction: Dimensions of Patient Autonomy and Non-adherence to Treatment Front. Psychol., 14 August 2019. https://doi.org/10.3389/fpsyg.2019.01857.

[3] Laura Sedig. What's the Role of Autonomy in Patient- and Family-Centered Care When Patients and Family Members Don't Agree? AMA J Ethics. 2016;18(1):12-17 https://doi.org/10.1001/journalofethics.2017.18.1.ecas2-1601.

[4] Sandman L, Munthe C. Shared decision making, paternalism and patient choice. Health Care Anal. 2010; 18(1):60-84. https://doi.org/10.1007/s10728-008-0108-6.

[5] O'Connor AM, Bennett CL, Stacey D, Barry M, Col NF, Eden KD, Entwistle VA, Fiset V, Holmes-Rovner M, Khangura S, Llewellyn-Thomas H, Rovner D. Decision aids for people facing health treatment or screening decisions (review). Cochrane Database of Systematic Reviews, 2009 issue 1. https://doi.org/10.1002/14651858.CD001431.pub2.

[6] Benson P. Feeling crazy': self-worth and the social character of responsibility. In: Mackenzie C, Stoljar N, editors. Relational autonomy: feminist perspectives on autonomy, agency and the social self. New York: Oxford University Press; 2000. pp. 72-93. 